\title{
A randomised controlled trial of bumetanide in the treatment of autism in children
}

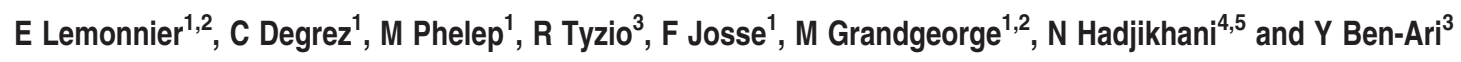

Gamma aminobutyric acid (GABA)-mediated synapses and the oscillations they orchestrate are altered in autism. GABA-acting benzodiazepines exert in some patients with autism paradoxical effects, raising the possibility that like in epilepsies, GABA excites neurons because of elevated intracellular concentrations of chloride. Following a successful pilot study, ${ }^{1}$ we have now performed a double-blind clinical trial using the diuretic, chloride-importer antagonist bumetanide that reduces intracellular chloride reinforcing GABAergic inhibition. Sixty children with autism or Asperger syndrome (3-11 years old) received for 3 months placebo or bumetanide (1 mg daily), followed by 1-month wash out. Determination of the severity of autism was made with video films at day 0 (D0) and $\mathrm{D} 90$ by blind, independent evaluators. Bumetanide reduced significantly the Childhood Autism Rating Scale (CARS) (D90 - D0; $\boldsymbol{P}<0.004$ treated vs placebo), Clinical Global Impressions $(\boldsymbol{P}<0.017$ treated vs placebo) and Autism Diagnostic Observation Schedule values when the most severe cases (CARS values above the mean \pm s.d.; $n=9$ ) were removed (Wilcoxon test: $P$-value $=0.031$; Student's $t$-test: $P$-value $=0.017$ ). Side effects were restricted to an occasional mild hypokalaemia (3.0-3.5 $\mathrm{mM} \mathrm{I}^{-1} \mathrm{~K}^{+}$) that was treated with supplemental potassium. In a companion study, chronic bumetanide treatment significantly improved accuracy in facial emotional labelling, and increased brain activation in areas involved in social and emotional perception (Hadjikhani et al., submitted). Therefore, bumetanide is a promising novel therapeutic agent to treat autism. Larger trials are warranted to better determine the population best suited for this treatment.

Translational Psychiatry (2012) 2, e202; doi:10.1038/tp.2012.124; published online 11 December 2012

\section{Introduction}

Autism is an early-onset pervasive developmental disorder associated with social disability, communication impairments, repetitive behaviours and restricted interests (ICD-10). ${ }^{2,3,4-6}$ Genetic mutations that have an impact on synapse operation $^{7-13}$ and environmental factors during pregnancy and delivery ${ }^{14-17}$ contribute to autism.

GABAergic signals are altered in autism as evidenced by the following:

(i) The excitation/inhibition ratio is modified in experimental models; ${ }^{12,17-21}$

(ii) Gamma-and other frequency-oscillations that are instrumental in higher cognitive functions, ${ }^{22-24}$ and generated by GABAergic neurons, ${ }^{20,25-27}$ are reduced in autism; ${ }^{28-31}$

(iii) In some patients, Gamma aminobutyric acid (GABA)acting benzodiazepines increase anxiety ${ }^{32}$ and decrease catatonia when other treatments fail. ${ }^{33-38}$ Other studies using paired pulses of auditory evoked potentials or transcranial magnetic stimuli ${ }^{39,40}$ have, however, observed no alterations of inhibition. Phenobarbital is less efficient for severe seizures, ${ }^{41}$ aggravates paradoxically electroence- phalogram discharges ${ }^{42,43}$ and is associated with high rates of complications, ${ }^{44}$ suggesting that GABA may excite neurons instead of inhibiting them in epilepsies. Elevated levels of intracellular chloride $\left(\left[\mathrm{Cl}^{-}\right]_{\mathrm{i}}\right)$ that shift the polarity of the actions of GABA from inhibition to excitation are observed in epileptic neurons and underlie the paradoxical actions of phenobarbital. ${ }^{45-50}$ These observations suggest that reducing the intracellular concentration of chloride may provide a useful treatment for autism.

The intracellular levels of chloride are primarily controlled by two chloride co-transporters-the chloride importer NKCC1 and the chloride exporter KCC2. ${ }^{48,51,52}$ The diuretic bumetanide is a high-affinity-specific NKCC1 antagonist that reduces $\left[\mathrm{Cl}^{-}\right]_{\mathrm{i}}{ }^{53}$ Bumetanide decreases the paradoxical actions of phenobarbital in epilepsies ${ }^{47,49,54,55}$ and is presently tested in neonatal encephalopathic epilepsies in European and US clinical trials (NCT01434225-NCT00830531). Bumetanide has been used since 1975 in adults and since 1986 in children to treat hypertension, broncho-pulmonary dysplasia, nephritic syndromes or heart congestions, and its pharmacokinetic is well known. ${ }^{56}$ The use of bumetanide is safe, provided that it is accompanied with clinical and biological surveillance in children to check hypokalaemia.

\footnotetext{
${ }^{1}$ Centre de Ressources Autisme de Bretagne, CHRU Brest Hôpital Bohars, Route de Ploudalmezeau, Bohars, France; ${ }^{2}$ Hôpital Bohars, Route de Ploudalmézeau, Bohars, France; ${ }^{3}$ INMED, INSERM U901, Université de la Méditerranée, Campus Scientifique de Luminy, Marseille, France; ${ }^{4}$ EPFL GHRAD, SV-BMI, AAB133, Station 19, Lausanne, Switzerland and ${ }^{5}$ Harvard Medical School/MGH/MIT, Martinos Center for Biomedical Imaging, Charlestown, MA, USA Correspondence: Professor E Lemonnier, Centre de Ressources Autisme de Bretagne, CHRU Brest Hopital Bohars, Route de Ploudalmezeau, Bohars, France or Dr Y Ben-Ari, INMED, INSERM U901, Université de la Méditerranée, Campus Scientifique de Luminy, BP 13 Cedex 09, 13273 Marseille, France.

E-mail: eric.lemonnier@chu-brest.fr or yehezkel.ben-ari@inserm.fr

Keywords: autism; bumetanide; clinical trial; diuretics; GABA

Received 4 October 2012; accepted 7 October 2012
} 
Following an encouraging pilot open trial, ${ }^{1}$ we performed a double-blind randomised study using chronic administration of bumetanide (3 months, $1 \mathrm{mg}$ daily) to children with autism/ Asperger (A/A). We show that the diuretic reduces significantly the severity of A/A with little side effects. In a parallel study, bumetanide improved accuracy in facial emotional labelling, and increased brain activation in areas involved in social and emotional perception (Hadjikhani et al., submitted). Our results pave the way for larger trials to develop this novel therapeutic strategy.

\section{Material and methods}

In June 2009, following our successful pilot study on five A/A children, ${ }^{1}$ we obtained the authorisation from the ad hoc committee of the Brest hospital to proceed with a double-blind (60 children) randomised trial in $\mathrm{A} / \mathrm{A}$ using bumetanide (Committee of Persons Protections—west 6-570-6/4/2009). The trial was approved by the French Health Products Safety Agency (AFFSAPS-A90936-66, 4 December 2009), clinical registration number NCT01078714. Written informed consent was obtained from each parent or legal guardian. The study was conducted in accordance with the provisions of the declaration of Helsinki (1996) and Good Clinical Practice guidelines.

Participants. Subjects were 3-11 years old children who met the ICD-10 (World Health Organisation 92) criteria for autistic disorders. This age range was selected as we receive primarily that age in the Centre de Ressources Autisme, and our wish to concentrate on this age to restrict the population recruited. Diagnosis was confirmed by ADI-R and Autism Diagnostic Observation Schedule (Generic) (ADOS G) ${ }^{57}$ revised in $1994,{ }^{5}$ also see Lord et al., ${ }^{6}$ with a diagnosis of autism $(F 84,0)$ or Asperger syndrome $(F 84,5)$ and a Childhood Autism Rating Scale (CARS) $\geqslant 30$. A child psychiatrist (EL) with more than 10 years experience made the diagnostic, reviewed medication histories before enrolment and determined if the inclusion criteria were satisfactorily met. We did not exclude any child from the assay relying on the severity of the syndrome as we did not know on which population the treatment would be beneficial. All patients had karyotypes and Fragile $X$ tests. Patients were excluded if they had karyotype abnormalities and/or neurological antecedents (including epilepsies and febrile seizures). Patients had no history of allergies to sulfonamides, hepatic, renal dysfunction or electrocardiogram abnormalities. Other treatments-with the exception of melatonin (1-4 mg) for sleep disorders-were stopped at least 3 weeks before entering the trial.

Treatment. The Centre of Clinical Investigation of Brest specialised in designing clinical trials developed the design and concept of the study. The direction of clinical research of the hospital provided external supervisors to follow the implementation of the trial. The hospital pharmacy made undistinguishable tablets using pure bumetanide powder or lactose that matched for smell, taste or viscosity. The preparation of the active and placebo tablets was made in accordance with European procedures.

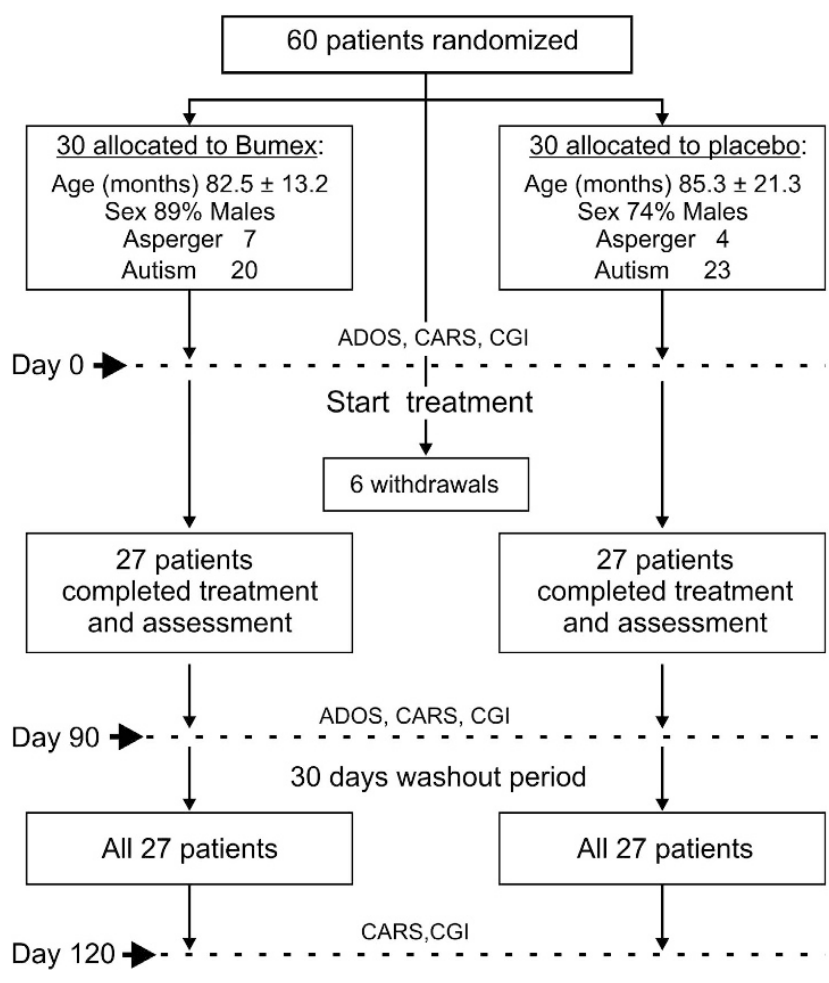

Figure 1 Schematic diagram of the protocol used. A total of 60 children were recruited for the trial, 6 withdrew for various reasons (see text) and the remaining 54 completed treatments and assessment. The video film was not available for one child and thus ADOS could not be performed. Tests included CARS at DO, 90 and 120 after 1-month wash out, CGI at D0, 90 and 120, and ADOS at D0 and 90.

As shown in Figure 1, the surveillance was performed once a week after the onset of the treatment, then monthly until the end of the treatment. It included checking orthostatic hypotension, allergy, cramps, asthenia, diarrhoea, myalgia, arthralgia, vertigo and nausea and conventional blood tests ( $\gamma$-glutamyltransferase, transaminases, alkaline phosphatases, glycaemia, uric acid and creatine). A summary of the conduction of the trial is shown in Figure 1.

Randomisation and blinding. The double-blind, randomised, placebo-controlled trial of bumetanide was conducted by the Centre de Ressources Autisme de Bretagne. Patients were randomly assigned to receive either bumetanide or placebo ( $0.5 \mathrm{mg}$ twice a day) fabricated by the pharmacy of the hospital. The trial was conducted between June 2009 and June 2010 and consisted in 3-month treatment (bumetanide or placebo) followed for all patients (placebo and treated) by a 1-month wash out. The evaluators (CD, MP, FJ, MG and EL) were fully blind to the drugs as the labelling was disclosed by the pharmacy only after the end of the 4-month trial and wash-out periods. The data, collected in the written questionnaires and video films of the meetings with the evaluators, were reported in case report forms to the data management and coordinating centre, where they were securely held and analysed. At the end of the 3-month double-blind phase, all children were removed from treatment during a 1-month wash-out period. 
Study assessment. The primary outcome was the CARS:

- The CARS is a behaviour-rating scale used to assess the presence and severity of the symptoms of autism spectrum disorder (ASD), and can be used to determine alterations during time and efficacy of treatments. ${ }^{58-62}$ The notation was obtained during a filmed session when the children were placed in a game and animated discussion with caregiver. The films were subsequently analysed (by $C D, M P, F J$ and $M G$ ) and a discussion with the parents made to gain more information. In one case, video was not available and, therefore, the CARS was determined relying only on the parent interview, and ADOS could not be made for this child (Figure 1). The CARS is composed of 15 items and the notation is from 1 to 4 with intermediary notes (1.5, 2.5 and so on). A score of $\geqslant 36$ is considered indicative of a severe autistic behaviour, and between 30 and 36 , a score indicate a mild-to-moderate autistic disorder. The total score is calculated by adding the notes of the 15 items complemented by the number of items with a score $\geqslant 3$.

The secondary outcome were:

- The Clinical Global Impressions (CGI) rated by the evaluating clinician to rate the severity of illness, change over time and efficacy of medication. CGI is used in the majority of clinical trials to examine disease severity and has been used with novel generation psychotic agents. ${ }^{63}$ It is composed of an estimation of the severity of ASD (at day 0), the CGlimprovement scale and the CGI-efficacy index (at D90).

- The ADOS G is a semi-structured, standardised assessment of social interaction, communication, play and imaginative use of materials for individuals suspected of having ASDs. ${ }^{5,6}$ The observational schedule consists of four modules, each administered to different individuals according to their level of expressive language. Each sequence is of $20-40 \mathrm{~min}$ and is video recorded. In keeping with earlier studies, ${ }^{5,64,65}$ we used the total score of all items and the individual subscales: A: communication and language, B: reciprocal social interactions, C: games, D: stereotyped behaviour and restricted interest and E: other abnormal behaviours.

Statistical analysis. Improvement between D0 and D90 was defined as the value at D0 minus the value at D90 for the CARS. In addition, we compared D90 with D120 for CARS to gain some information on the alterations during the wash-out period. Improvements were compared between treated and placebo groups using analysis of covariance with adjustment for the initial value. Graphical tools and Shapiro-Wilk test were used to assess residuals normality.

Improvements between D0 and D90 on the ADOS scales and subscales were analysed by comparing CGI values at D90 between treated and placebo groups using Wilcoxon rank test. In addition, CARS and number of items $>3$ in the CARS score were compared between D0 and D90 for each group, using paired $t$-test. Statistical analyses were performed using SAS version 9.1 and were based on the intention-to-treat principle. All tests were two-sided and $P$-values $<0.05$ were considered as significant.

\section{Results}

Of the 103 children who were screened for the study, 43 did not meet the criteria for enrolment, or the parents or children
Table 1 CARS and CGI tests

\begin{tabular}{lcrl}
\hline & Bumetanide & Placebo & Statistics \\
\hline CARS D0 & $41.6 \pm 3.6$ & $41.1 \pm 4.1$ & \\
CARS D90 & $36 \pm 5.7$ & $39.3 \pm 4.9$ & \\
Gain CARS D90 - D0 & $5.6 \pm 4$ & $1.8 \pm 5.1$ & $P=0.0044$ \\
Number of items > 3 D0 & $9.6 \pm 2.2$ & $9.8 \pm 2.5$ & \\
Number of items > 3, D90 & $6.2 \pm 3$ & $8.1 \pm 2.9$ & \\
Gain number of items D90-D0 & $3.4 \pm 2.5$ & $1.7 \pm 3.3$ & $P=0.017$ \\
CARS D120 & $38.8 \pm 4.7$ & $40.5 \pm 3.8$ & \\
Loss CARS D90-D120 & $2.9 \pm 3.0$ & $1.2 \pm 3.7$ & \\
Number of items > 3 D120 & $8.0 \pm 2.7$ & $9.1 \pm 2.1$ & \\
loss number of items > 3 & $1.8 \pm 1.9$ & $1.0 \pm 2.2$ & \\
CGI (therapeutic index) & $2.04 \pm 0.87$ & $1.56 \pm 0.85$ & $P=0.017$ \\
\end{tabular}

Abbreviations: ASD, autism spectrum disorder; CARS, Childhood Autism Rating Scale; CGI, Clinical Global Impressions.

Effects of bumetanide on ASD severity. Note the significant reduction of the severity of CARS after 90 days. Note also the significant amelioration of the CGI index. The values of CARS are indicated at D0, 90 and 120 (after 30-day wash out). The gain in CARS numbers between D90 and D0 are noted, as well as the number of items $>3$ at D0 and D90 and the differences between D90 and D0.

declined participation. The remaining 60 children (details in Supplementary Tables 1 and 2) were randomly assigned to receive either bumetanide ( $1 \mathrm{mg}$ daily) or placebo during 3 months followed by a wash-out period of 1 month (Figure 1). Baseline characteristics of the patients were similar in the bumetanide and placebo groups (Supplementary Table 1). In all, 24 patients did not speak (10 treated/14 placebo), 8 used a few words but no sentences $(5 / 3)$ and 28 spoke correctly (15/13). Six children discontinued the trial shortly after the start, two patients $(n=1$ in each group) for enuresis (Supplementary Table 4), two consequently to delayed consequences of a late arrest of the drugs they were treated with (methylphenidate and risperidone), one because of hypokalemia $\left(3.1 \mathrm{mMI}^{-1} \mathrm{~K}^{+}\right.$ found at the end of trial to be on bumetanide) and one for allergia/eczema (found at the end of the trial to be on placebo). All other patients (54: found subsequently to be composed of 27 treated and 27 placebo) completed the planned programme (Figure 1).

The CARS test. The CARS revealed a statistically significant amelioration of total score $(P=0.004$; Table 1). After 90 days of bumetanide, the treated groups shifted from severe (CARS >36.5) to mild or medium severity $(<36.5)$. In contrast, there was no significant difference in the placebo group between D0 and D90 (Table 1). The number of items $>3$ shifted from 9.6 to 6.2 in the bumetanide-treated group and from 9.8 to 8.1 in the placebo group $(P=0.017)$. These differences are also visible in the plots of the ensemble values from all placebo and treated individuals (Figure 2, also see Supplementary Table 6). Interestingly, although not statistically significant, there was a clear trend to return to pretreatment values at the end of the 1-month wash-out period (35.9 $\pm 1.1-38.8 \pm 0.9$ for bumetanide-treated and $39.3 \pm 0.9-40.5 \pm 0.7$ for the placebo group).

The CGI test. A clinical amelioration with little side effects is suggested by the therapeutic index of CGI (from 2.04 to 1.56, $P=0.017$ ) (Table 1). As shown in Table 2, we observed 33\% 


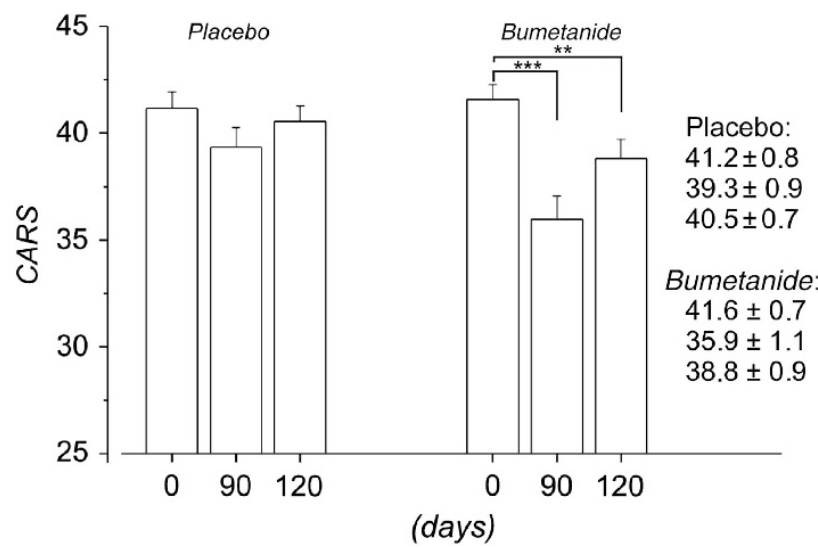

Figure 2 All the values obtained with CARS are depicted. Note the significant differences between placebo and bumetanide treated patients and a partial return to pretreatment values after 1-month wash-out period. The number of items $>3$ was also significantly reduced as shown at the right side of the figure (number corresponding to D0, D90 and D120; ${ }^{* \star *} p<0.005$ for D90 and ${ }^{* *} p<0.05$ for D120).

Table 2 Amelioration in CGI produced by bumetanide

\begin{tabular}{lcccc}
\hline Score CGI & \multicolumn{2}{c}{ Bumetanide (n/\%) } & \multicolumn{2}{c}{ Placebo (n/\%) } \\
\hline 2: significant amelioration & $14 / 51.8 \%$ & $77.7 \%$ & $6 / 22.2 \%$ & $33.3 \%$ \\
3: small amelioration & $7 / 25.9 \%$ & & $3 / 11.1 \%$ & \\
4: no amelioration & $6 / 22.2 \%$ & & $18 / 66.6 \%$ & \\
& & & & \\
\end{tabular}

Abbreviation: CGI, Clinical Global Impressions.

Note that $77.7 \%$ of children had a small or significant amelioration with the diuretic to be compared with only $33.3 \%$ in placebo. Conversely, $22.2 \%$ had no amelioration with the diuretic and $66.6 \%$ in placebo.

amelioration with placebo-a quite usual observation-but $77 \%$ with bumetanide.

The Autism Diagnostic Observation Schedule. We first used the ADOS test to determine the effects of the treatment (26 patients-the movie was unavailable for one patient, see Figure 1) versus placebo (27 patients). The total score and the subscales (A-E) were pooled (total 41 notes varying from 0 to 3 ) and tested at $t=0$ and 90 . Gains in total and per category scores were compiled for placebo and bumetanide-treated patients. Average gains of ADOS total scores increased moderately for treated ( mean $=7.8$, s.d. $=7.4$ ) versus placebo (mean $=5.3$, s.d. $=6.6$ ) patients (Figure 1). However, this difference was not significant using Wilcoxon test $(P$ value $=0.178$ ) and only $10 \%$ significant using the unilateral Student's $t$-test $(P$-value $=0.099)$. We then subdivided the analysis relying on the subscales (that is, A-E criteria). Of these five subscales, only $D$ (stereotyped behaviour and restricted interest) was significant (Wilcoxon test $P$ value $=0.001)$. (Table 3, also see Supplementary Table 5).

Because of the heterogeneity of the population, we reasoned that the treatment might differently have an impact on patients according to the severity of ASD as diagnosed with the CARS. Using the CARS values (ranking between 34 and 48.5 with a mean of 41.4 ), we segregated patients having the
Table 3 ADOS tests: differences between bumetanide and placebo

\begin{tabular}{|c|c|c|}
\hline $\begin{array}{l}\text { Gains in } 90 \text { days for various tested criteria } \\
\text { (Wilcoxon test) }\end{array}$ & $\begin{array}{l}\mathrm{P}- \\
\text { value }\end{array}$ & $\begin{array}{l}\text { Significance } \\
\text { level }\end{array}$ \\
\hline \multicolumn{3}{|l|}{ Tests ADOS } \\
\hline Total (ABCDE) & 0.1783 & \\
\hline Total A & 0.4085 & \\
\hline Total B & 0.7953 & \\
\hline Total C & 0.6453 & \\
\hline Total D & 0.002 & $<0.01$ \\
\hline Total E & 0.8904 & \\
\hline \multicolumn{3}{|l|}{ Tests on ADOS total scores according to CARS } \\
\hline Total (ABCDE) for CARS < average + s.d. & 0.0316 & $<0.05$ \\
\hline Total A for CARS < average + s.d. & 0.3727 & \\
\hline Total B for CARS < average + s.d. & 0.3741 & \\
\hline Total C for CARS < average + s.d. & 0.7837 & \\
\hline Total D for CARS < average + s.d. & 0.002 & $<0.01$ \\
\hline Total E for CARS < average + s.d. & 0.2864 & \\
\hline Total $(A B C D E)$ for CARS $>$ average - s.d. & 0.4029 & \\
\hline Total A for CARS > average - s.d. & 0.8306 & \\
\hline Total B for CARS > average - s.d. & 0.9151 & \\
\hline Total C for CARS > average - s.d. & 0.3111 & \\
\hline Total D for CARS > average - s.d. & 0.0312 & \\
\hline Total E for CARS > average - s.d. & 0.3811 & \\
\hline
\end{tabular}

Abbreviations: ADOS, Autism Diagnostic Observation Schedule; CARS, Childhood Autism Rating Scale.

Global ADOS values are not significantly different (total $P$-value 0.1783 ). Values per criteria are also not significantly different except criterion D (hyperactivity and restricted interest; 0.002). The ADOS values are then compared after removing the most and least severe cases assessed relying on CARS. When the most severe cases (nine) are removed (> mean + s.d.), the difference treatment/placebo is significant for the total value $(P=0.0316)$ and for $\mathrm{D}$ criterion $(P=0.002)$. In contrast, the differences are not significant when the least severe cases are removed $<$ average - s.d.).

highest or lowest CARS scores, that is, more or less than the mean \pm s.d. (41.4 \pm 3.9) corresponding to the most or least severely affected children, respectively. In all, 9 out of 53 patients had CARS scores $>45.2$ (mean \pm s.d.: two bumetanide and seven placebo), suggesting high severity. As shown in Figure 3, bumetanide ameliorated total ADOS scores significantly of the 44 remaining patients (24 bumetanide/20 placebo; Wilcoxon: $P$-value $=0.031$; Student's $t$-test: $P$-value $=0.017)$. In contrast (Figure 3$)$, when the patients with CARS scores $<37.5$ (mean \pm s.d.; three bumetanide and six placebo) were segregated, the effects of treatment on ADOS total scores of the 44 remaining patients (21 placebo and 23 bumetanide) were not significant (Figure 3; Wilcoxon: $P$-value $=0.4$; Student's $t$-test: $P$-value $=0.26)$. These observations suggest that the treatment is more efficient in less severely affected children.

Safety and tolerability of the treatment. The only child that was removed from the trial because of eczema was on placebo (Supplementary Table 4). Two children were removed from the trial on parental decision because of bed-wetting and identified at the end of the trial to have been treated with placebo (one) and bumetanide (one). Two children were removed from the trial consequently to hyperactivity due to withdrawal from their medication (methylphenidate and risperidone); although that was stopped 3 weeks before the trial (Figure 1). One child treated with bumetanide was removed because of hypokalemia $(n=1)$ (Supplementary 

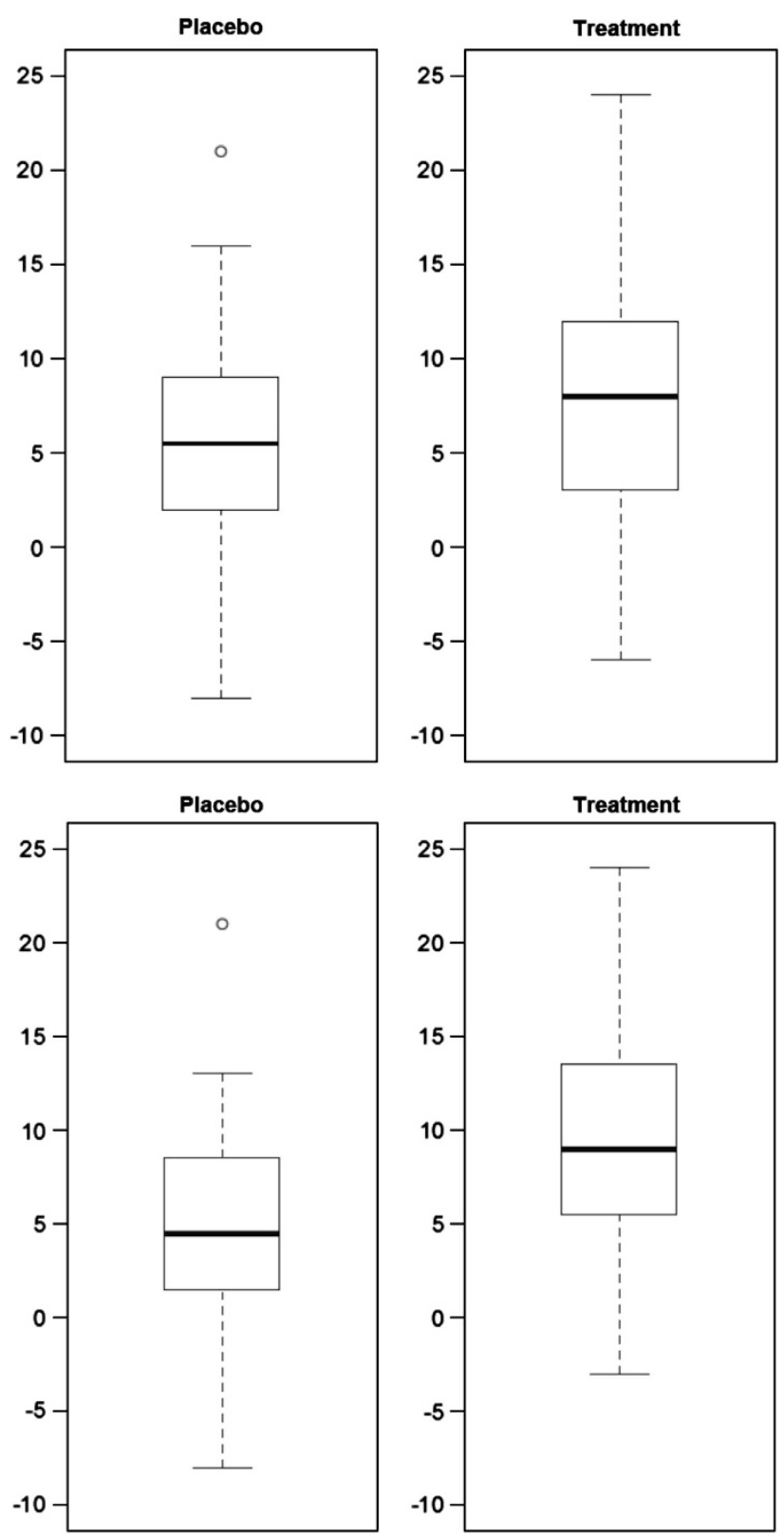

Figure 3 Top figure: Boxplot of ADOS total scores gains between the beginning and the end of the trial (90 days later) for patient receiving placebo (left panel) and treatment (right panel). Bottom: Boxplot of ADOS total scores gains but excluding patients with 'above normal' CARS scores (that is, above mean \pm s.d.) - between the beginning and the end of the trial (90 days later) for patient receiving placebo (left panel) and treatment (right panel).

Table 4). When the levels of $\mathrm{K}^{+}$were $\leqslant 3,5 \mathrm{mMl}^{-1}$, we supplemented with potassium-gluconate syrup. This was necessary in six of the bumetanide-treated children that had a mild hypokalemia $\left(3.5,3.4,3.1,3.5,3.5\right.$ and $\left.3.4 \mathrm{ml}^{-1}\right)$. Clinical and Biological surveillance revealed no alterations in all the parameters that were checked (see Treatment). There was no dehydration, as confirmed by normal sodiums and maintenance of weight (Supplementary Table 3). Therefore, in keeping with the extensive use of bumetanide in babies and children for several decades, the side effects in the present trial were limited.

Qualitative illustrations. Two individual cases are detailed below and depicted in the movies joined to this article (http:// vimeo.com/48520450; http://vimeo.com/48726291).

Case A (Al): a 6-year-old boy, with poor language capacity, a high level of stereotyped behaviour, little social interaction, hyperactivity and oppositional behaviour. No medication before trial onset. He went for 5 half days a week to the children hospital, two sessions of language therapy weekly and public school to which he went 3 half days weekly with caregiver. After 3 months of treatment, his parents, teachers and caregivers at hospital and friends at school attested that he participated significantly better and in social games with the psychologist (see movie). He also had an improved nonverbal communication (eye contact and attention). The child remained under treatment for over 18 months.

Case $B(\mathrm{Cl})$ : a 9-year-old boy, with good language capacity (full spontaneous sentences), poor social exchange, restricted social interactions, little eye-to-eye communication, hyperactive and stereotyped behaviour. He goes to public school with the help of a caregiver and has one weekly session of re-education. No medication before trial onset. After 3 months of treatment, there was a clear amelioration of eye contact, communication exchange and social communication, reduction of hyperactivity and increased 'presence' with family and friends at school.

Several qualitative comments of the parents attest to its positive effects, including a greater presence of the child, facilitated visual communication and social exchanges. In keeping with this, at the end of the wash-out period, almost all the parents demanded to shift (continue) to bumetanide treatment; 87 patients are presently treated with bumetanide, some for 2 year. Supplemental potassium is provided to $30 \%$ of them.

\section{Discussion}

These results confirm and extend an earlier small open-label pilot study that to the best of our knowledge was the first to use bumetanide in autism. Our aims here were to test the adverse effects of long-term treatment on child behaviour and the therapeutic actions of bumetanide in A/A children independently of developmental levels, leading to a rather heterogeneous population. Our finding should be interpreted in light of these limitations and the lack of other tests like the Social Responsiveness Scale, which could have been useful. In spite of these limitations, bumetanide reduced the severity of the symptoms, the parents used literally the same words to stress that the children are more 'present' with enhanced communication with their environment. Using a similar treatment paradigm, Hadjikhani et al. have recently found an amelioration of emotive face recognition in seven Asperger children after treatment and activation after treatment of brain regions involved in face recognition and emotion that were not activated before (Hadjikhani et al., submitted). Therefore, although the treatment does not 'cure' autism, the amelioration it produces is of sufficient interest so as to invite larger 
cohorts to test its effects on atypical autism and, possibly, unspecific pervasive developmental disorders.

The CARS has been extensively used as a screening instrument to assess the changes in symptoms of autism over time..$^{58,59}$ It is also used to assess the therapeutic potentials of putative agents ${ }^{61,62,66}$ and has been favourably compared with tests of risperidone and aripiprazole in the treatment of autism ${ }^{60,67,68}$ (also see refs 68-70). Other studies have used the same scales; ${ }^{71-74}$ also, see the three double-blind trials with aripiprazole versus placebo. ${ }^{74-76}$ The CARS has also superior hit rate and less false-positive identifications than $A B C$ or other tests. ${ }^{61,68,77-79}$ The therapeutic usefulness and the benefit/risk ratio was also shown with the widely used CGI, revealing a significant amelioration with little side effects. Finally, with ADOS, there was a statistically significant amelioration when the most, but not the least, severe cases (above mean \pm s.d.) were removed, suggesting that the diuretic is less efficient to treat severely affected children with autism.

Direct evidence that bumetanide exerts its actions by reducing intracellular chloride in central neurons in humans is lacking. In epilepsies, bumetanide reduces the severity of seizures in experimental animals in vivo and in vitro (see above). The MECP2 genetic mutations involved in Rett syndrome like embryonic valproate alter the expression of the trophic factor BDNF that controls the intracellular chloride levels, providing a link between ASD and intracellular chloride. ${ }^{47,80-86}$ In keeping with this, in vivo administration of bumetanide to pups reduces GABA-generated network activities, suggesting a central action of the diuretic ${ }^{87}$ in spite of its poor blood brain barrier permeability and relatively short lifetime. ${ }^{88}$ Also, we have recently found significant reduction of intracellular chloride levels in cortical neurons of two animal models in slices Fragile $\mathrm{X}$ and in utero valproate (Tyzio et al., in preparation). Collectively, these observations are compatible with a central action of bumetanide, although more investigations in humans are required. Our long-lasting twicedaily regimen adopted subsequently in our continuous open trials may be helpful in that regard. Finally, only a small hypokalaemia was observed in $30 \%$ of the children; this was readily compensated with $\mathrm{K}^{+}$syrup. Therefore, in keeping with an extensive use of bumetanide for decades, the use of bumetanide in chronic conditions is safe with little side effects.

Summing up, our results suggest a promising a novel therapeutic approach to treat ASD children. Our results call for larger multicentre trials with more restricted inclusion and exclusion criteria and more extended investigations on the dose/response actions of the diuretic. A particularly significant improvement may be expected with an early diagnostic and treatment initiation.

\section{Conflict of interest}

All the authors have no conflict of interest, no financial and personal relationships with other people or organisations including employment, consultancies, stock ownership, honoraria, paid expert testimony, and travel grants all during the conduction and termination of the work submitted. An application patent on the use of diuretics has been deposited by the French medical research council on the basis of our clinical results. Subsequent to completion of this study (finished in June 2010), one of the authors (Y B-A) has become (in 2012) the CEO and a major shareholder of a company (Neurochlore), seeking to develop and commercialize bumetanide as a treatment for autism.

Acknowledgements. We are extremely grateful to Dr Tamara Ben-Ari for support in the statistical analysis and elegant ideas. We also thank Profs G Holmes, A Represa, $\mathrm{R}$ Pressler and $\mathrm{O}$ Dulac for their suggestions. We also thank Mss $F$ Morvan, M-H Lallier and C Dolou from the hospital of Brest for support in the trial management, and $\mathrm{K}$ Metrailler and $\mathrm{C}$ Schwab-Burget for their help with logistics. $\mathrm{H}$ Lacut and E Nowak are thanked for their help in organising the trial and in the statistical analysis. The funding sources were primarily the Brest Public Hospital, INMED funds (to YB-A) and the Child Psychiatry Department and Swiss National Science Foundation grant PP00P3_130191 (to NH). An ERC senior grant on this study was rejected (to YB-A).

1. Lemonnier E, Ben-Ari Y. The diuretic bumetanide decreases autistic behaviour in five infants treated during 3 months with no side effects. Acta Paediatr 2010; 99: 1885-1888.

2. Courchesne E, Mouton PR, Calhoun ME, Semendeferi K, hrens-Barbeau C, Hallet MJ et al. Neuron number and size in prefrontal cortex of children with autism 1. JAMA 2011; 306: 2001-2010.

3. Khan NZ, Gallo LA, Arghir A, Budisteanu B, Budisteanu M, Dobrescu I et al. Autism and the grand challenges in global mental health. Autism Res 2012; 5: 156-159.

4. Elsabbagh M, Divan G, Koh YJ, Kim YS, Kauchali S, Marcin C et al. Global prevalence of autism and other pervasive developmental disorders. Autism Res 2012; 5: 160-179.

5. Lord C, Rutter M, Le CA. Autism diagnostic interview-revised: a revised version of a diagnostic interview for caregivers of individuals with possible pervasive developmental disorders. J Autism Dev Disord 1994; 24: 659-685.

6. Lord C, Risi S, Lambrecht L, Cook EH, Leventhal BL, DiLavore PC et al. The autism diagnostic observation schedule-generic: a standard measure of social and communication deficits associated with the spectrum of autism. J Autism Dev Disord 2000; 30: $205-223$

7. Jamain S, Quach H, Betancur C, Rastam M, Colineaux C, Gillberg IC et al. Mutations of the $X$-linked genes encoding neuroligins NLGN3 and NLGN4 are associated with autism. Nat Genet 2003; 34: 27-29.

8. Bourgeron T. A synaptic trek to autism. Curr Opin Neurobiol 2009; 19: 231-234.

9. Laumonnier F, Bonnet-Brilhault F, Gomot M, Blanc R, David A, Moizard MP et al. X-linked mental retardation and autism are associated with a mutation in the NLGN4 gene, a member of the neuroligin family. Am J Hum Genet 2004; 74: 552-557.

10. Giannandrea M, Bianchi V, Mignogna ML, Sirri A, Carrabino S, D'Elia E et al. Mutations in the Small GTPase Gene RAB39B are responsible for x-linked mental retardation associated with autism, epilepsy, and macrocephaly. Am J Hum Genet 2010; 86 185-195.

11. Weiss LA. Autism genetics: emerging data from genome-wide copy-number and single nucleotide polymorphism scans. Expert Rev Mol Diagn 2009; 9: 795-803.

12. Tabuchi K, Blundell J, Etherton MR, Hammer RE, Liu X, Powell CM et al. A neuroligin-3 mutation implicated in autism increases inhibitory synaptic transmission in mice. Science 2007; 318: 71-76

13. Chubykin AA, Atasoy D, Etherton MR, Brose N, Kavalali ET, Gibson JR et al. Activitydependent validation of excitatory versus inhibitory synapses by neuroligin-1 versus neuroligin-2. Neuron 2007; 54: 919-931

14. Croen L, Grether JK, Yoshida CK, Odouli R, Hendrick V. Antidepressant use during pregnancy and childhood autism spectrum disorders. Arch General Psychiatry 2011; 68 1104-1112.

15. Patterson PH. Immune involvement in schizophrenia and autism: etiology, pathology and animal models. Behav Brain Res 2009; 204: 313-321.

16. Kemper TL, Bauman M. Neuropathology of infantile autism. J Neuropathol Exp Neurol 1998; 57: 645-652.

17. Dossche DM. GABA in autism. international review of neurobiology. vol. 71. Academic Press: Amsterdam, 2005 pp 1-481.

18. Chao HT, Chen HM, Samaco RC, Xue MS, Chahrour M, Yoo J et al. Dysfunction in GABA signalling mediates autism-like stereotypies and Rett syndrome phenotypes 1. Nature 2010; 468: 263-269.

19. Zhang C, Atasoy D, Arac D, Yang X, Fucillo MV, Robison AJ et al. Neurexins physically and functionally interact with GABA(A) receptors. Neuron 2010; 66: 403-416.

20. Pizzarelli R, Cherubini E. Alterations of gabaergic signaling in autsim spectrum disorders. Neural Plast 2011; 297: 1-12.

21. Gogolla N, LeBlanc JJ, Quast KB, Sudhof TC, Fagiolini M, Hensch TK. Common circuit defect of excitatory-inhibitory balance in mouse models of autism 1. J Neurodev Disord 2009; 1: 172-181

22. Singer W. Synchronization of cortical activity and its putative role in information-processing and learning 21. Annu Rev Physiol 1993; 55: 349-374. 
23. Lisman JE, Idiart MAP. Storage of $7+1-2$ short-term memories in oscillatory subcycles 1. Science 1995; 267: 1512-1515.

24. Murthy VN, Fetz EE. Coherent $25-\mathrm{Hz}$ to $35-\mathrm{Hz}$ oscillations in the sensorimotor cortex of awake behaving monkeys 1. Proc Natl Acad Sci USA 1992; 89: 5670-5674.

25. Lewis DA, Hashimoto T, Volk DW. Cortical inhibitory neurons and schizophrenia. Nat Rev Neurosci 2005; 6: 312-324.

26. Lisman JE, Coyle JT, Green RW, Javitt DC, Benes FM, Heckers S et al. Circuit-based framework for understanding neurotransmitter and risk gene interactions in schizophrenia. Trends Neurosci 2008; 31: 234-242.

27. Gogolla N, LeBlanc JJ, Quast KB, Sudhof TC, Fagiolini M, Hensch TK. Common circuit defect of excitatory-inhibitory balance in mouse models of autism. J Neurodev Disord 2009 ; 1: $172-181$.

28. Grice SJ, Spratling MW, Karmiloff-Smith A, Halit H, Csibra G, de Haan M et al. Disordered visual processing and oscillatory brain activity in autism and Williams syndrome. Neuroreport 2001; 12: 2697-2700.

29. Brown C, Gruber T, Boucher J, Rippon G, Brock J. Gamma abnormalities during perception of illusory figures in autism. Cortex 2005; 41: 364-376.

30. Wilson TW, Rojas DC, Reite ML, Teale PD, Rogers SJ. Children and adolescents with autism exhibit reduced MEG steady-state gamma responses. Biol Psychiatry 2007; 62 192-197.

31. Tierney AL, Gabard-Durnam L, Vogel-Farley V, Tager-Flusberg H, Nelson CA Developmental trajectories of resting EEG power: an endophenotype of autism spectrum disorder. Plos One 2012; 7(6)

32. Marrosu F, Marrosu G, Rachel M, Biggio G. Paradoxical reactions elicited by diazepam in children with classic autism. Funct Neurol 1987; 2: 355-361.

33. Wing L, Shah A. Catatonia in autistic spectrum disorders. Br J Psychiatry 2000; 176: 357-362.

34. Hutton J, Goode S, Murphy M, Le Couteur A, Rutter M. New-onset psychiatric disorders in individuals with autism. Autism 2008; 12: 373-390.

35. Ungvari GS, Kau LS, Wai-Kwong T, Shing NF. The pharmacological treatment of catatonia: an overview. Eur Arch Psychiatry Clin Neurosci 2001; 251: I31-I34.

36. Tibrewal P, Narayanaswamy J, Zutshi A, Srinivasaraju R, Math SB. Response rate of lorazepam in catatonia: A developing country's perspective. Prog Neuro-Psych Biol Psych 2010; 34: 1520-1522.

37. Fink M, Taylor MA, Ghaziuddin N. Catatonia in autistic spectrum disorders: a medical treatment algorithm. Int Rev Neurobiol 2006; 72: 233-244.

38. Ghaziuddin M, Quinlan P, Ghaziuddin N. Catatonia in autism: a distinct subtype? J Intellectual Disabil Res 2005; 49: 102-105

39. Orekhova EV, Stroganova TA, Prokofiev AO, Nygren G, Gillberg C, Elam M. Right hemispheric failure to respond to temporal novelty in autism: evidence from an eventrelated potential study. Int J Psychophysiol 2008; 69: 186.

40. Enticott PG, Rinehart NJ, Tonge BJ, Bradshaw JL, Fitzgerald PB. Repetitive transcrania magnetic stimulation (rTMS) improves movement-related cortical potentials in autism spectrum disorders. Brain Stimulation 2012; 5: 30-37.

41. Painter MJ, Scher MS, Stein AD, Armatti S, Wang ZM, Gardiner JC et al. Phenobarbital compared with phenytoin for the treatment of neonatal seizures. N Engl J Med 1999; 341 485-489.

42. Boylan GB, Rennie JM, Pressler RM, Wilson G, Morton M, Binnie CD. Phenobarbitone neonatal seizures, and video-EEG. Arch Dis Child Fetal Neonatal Ed 2002; 86: F165-F170.

43. Guillet $\mathrm{R}$, Kwon J. Seizure recurrence and developmental disabilities after neonata seizures: outcomes are unrelated to use of phenobarbital prophylaxis. J Child Neurol 2007; 22: 389-395.

44. Kaindl AM, Koppelstaetter A, Nebrich G, Stuwe J, Sifringer M, Zabel C et al. Brief alteration of NMDA or GABAA receptor-mediated neurotransmission has long term effects on the developing cerebral cortex. Mol Cell Proteomics 2008; 7: 2293-2310.

45. Huberfeld G, Wittner L, Clemenceau S, Baulac M, Miles R, Kaila K et al. Perturbed expression of the $\mathrm{K}-\mathrm{Cl}$ cotransporter $\mathrm{KCC} 2$ and GABAergic signalling in human temporal lobe epilepsy. Epilepsia 2006; 47: 9.

46. Cohen I, Navarro V, Clemenceau S, Baulac M, Miles R. On the origin of interictal activity in human temporal lobe epilepsy in vitro. Science 2002; 298: 1418-1421.

47. Nardou R, Yamamoto S, Chazal G, Bhar A, Ferrand N, Dulac 0 et al. Neuronal chloride accumulation and excitatory GABA underlie aggravation of neonatal epileptiform activities by phenobarbital. Brain 2011; 134: 987-1002.

48. Ben Ari Y, Gaiarsa JL, Tyzio R, Khazipov R. GABA: a pioneer transmitter that excites immature neurons and generates primitive oscillations. Physiol Rev 2007; 87: $1215-1284$

49. Dzhala VI, Talos DM, Sdrulla DA, Brumback AC, Mathews GC, Benke TA et al. NKCC transporter facilitates seizures in the developing brain. Nat Med 2005; 11: 1205-1213.

50. Payne JA, Rivera C, Voipio J, Kaila K. Cation-chloride co-transporters in neurona communication, development and trauma. Trends Neurosci 2003; 26: 199-206.

51. Rivera C, Voipio J, Payne JA, Ruusuvuori E, Lahtinen $\mathrm{H}$, Lamsa K et al. The $\mathrm{K}+/ \mathrm{Cl}-\mathrm{co}^{-}$ transporter KCC2 renders GABA hyperpolarizing during neuronal maturation. Nature 1999; 397: 251-255.

52. Delpire E. Cation-chloride cotransporters in neuronal communication. News Physiol Sci 2000; 15: 309-312.

53. Feit PW. Bumetanide-the way to its chemical structure. J Clin Pharmacol 1981; 21: 531-536.

54. Delpire E, Mount DB. Human and murine phenotypes associated with defects in cationchloride cotransport. Annu Rev Physiol 2002; 64: 803-843.
55. Blaesse P, Airaksinen MS, Rivera C, Kaila K. Cation-chloride cotransporters and neuronal function. Neuron 2009; 61: 820-838.

56. Sullivan JE, Witte MK, Yamashita TS, Myers CM, Blumer JL. Dose-ranging evaluation of bumetanide pharmacodynamics in critically ill infants. Clin Pharmacol Ther 1996; 60: 424-434.

57. Le Couteur A, Rutter M, Lord C, Rios P, Robertson S, Holdgrafer M et al. Autism diagnostic interview: a standardized investigator-based instrument. J Autism Dev Disord 1989; 19: 363-387.

58. Schopler E, Reichler RJ, DeVellis RF, Daly K. Toward objective classification of childhood autism: Childhood Autism Rating Scale (CARS). J Autism Dev Disord 1980; 10: 91-103.

59. DiLalla DL, Rogers SJ. Domains of the Childhood Autism Rating Scale: relevance for diagnosis and treatment. J Autism Dev Disord 1994; 24: 115-128.

60. Masi G, Cosenza A, Millepiedi S, Muratori F, Pari C, Salvadori F. Aripiprazole monotherapy in children and young adolescents with pervasive developmental disorders: a retrospective study. CNS Drugs 2009; 23: 511-521.

61. Geier DA, Kern JK, Davis G, King PG, Adams JB, Young JL et al. A prospective doubleblind, randomized clinical trial of levocarnitine to treat autism spectrum disorders. Med $\mathrm{Sci}$ Monit 2011; 17: 115-123.

62. Canitano R, Scandurra V. Psychopharmacology in autism: an update. Prog Neuro-Psych Biol Psych 2011; 35: 18-28.

63. Guy W. Assessment Manual for Psychopharmacology. Early Clinical Drug Evaluation Unit. National institute of mental health: Washington, DC, 2000.

64. Crowley JC, Katz LC. Development of ocular dominance columns in the absence of retinal input. Nat Neurosci 1999; 2: 1125-1130.

65. Owley T, McMahon W, Cook EH, Laulhere T, South M, Mays LZ et al. Multisite, doubleblind, placebo-controlled trial of porcine secretin in autism. J Am Acad Child Adolesc Psychiatry 2001; 40: 1293-1299.

66. Papauasiliou AS, Nikaina I, Rizou J, Alexandrou S. The effect of a psycho-educational program on CARS scores and short sensory profile in autistic children. Eur J Paediatr Neurol 2011; 15: 338-344.

67. Masi G, Cosenza A, Mucci M, Brovedani P. Open trial of risperidone in 24 young children with pervasive developmental disorders. J Am Acad Child Adolesc Psychiatry 2001; 40: 1206-1214.

68. Nagaraj R, Singhi P, Malhi P. Risperidone in children with autism: randomized, placebocontrolled, double-blind study. J Child Neurol 2006; 21: 450-455.

69. Canitano R, Scandurra V. Risperidone in the treatment of behavioral disorders associated with autism in children and adolescents. Neuropsychiatr Dis Treat 2008; 4: 723-730.

70. Luby J, Mrakotsky C, Stalets MM, Belden A, Heffelfinger A, Williams M et al. Risperidone in preschool children with autistic spectrum disorders: an investigation of safety and efficacy. J Child Adolesc Psychopharmacol 2006; 16: 575-587.

71. Shea S, Turgay A, Carroll A, Schulz M, Orlik H, Smith I et al. Risperidone in the treatment of disruptive behavioral symptoms in children with autistic and other pervasive developmental disorders. Pediatrics 2004; 114: E634-E641.

72. McDougle CJ, Stigler KA, Posey DJ. Pharmacological treatment of behavioral symptoms in autism. Neuropsychopharmacology 2005; 30: S72.

73. Pandina GJ, Aman MG, Findling RL. Risperidone in the management of disruptive behavior disorders. J Child Adolesc Psychopharmacol 2006; 16: 379-392.

74. Robb AS, Andersson C, Bellocchio EE, Manos G, Rojas-Fernandez C, Mathew S et al. Safety and tolerability of aripiprazole in the treatment of irritability associated with autistic disorder in pediatric subjects (6-17 years old):results from a pooled analysis of 2 studies. Prim Care Companion CNS Disord 2011; 13(1)

75. Benton TD. Aripiprazole to treat irritability associated with autism: a placebo-controlled, fixed-dose trial. Curr Psychiatry Rep 2011; 13: 77-79.

76. Marcus RN, Owen R, Manos G, Mankoski R, Kamen L, McQuade RD et al. Safety and tolerability of aripiprazole for irritability in pediatric patients with autistic disorder: a 52-week, open-label, multicenter study. J Clin Psychiatry 2011; 72: 1270-1276.

77. Eaves RC, Milner B. The criterion-related validity of the childhood autism rating-scale and the autism behavior checklist. J Abnorm Child Psychol 1993; 21: 481-491.

78. Ventola PE, Kleinman J, Pandey J, Barton M, Allen S, Green J et al. Agreement among four diagnostic instruments for autism spectrum disorders in toddlers. J Autism Dev Disord 2006; 36: 839-847.

79. Perry A, Condillac RA, Freeman NL, Dunn-Geier J, Belair J. Multi-site study of the childhood autism rating scale (CARS) in five clinical groups of young children. J Autism Dev Disord 2005; 35: 625-634.

80. Chen WG, Chang Q, Lin YX, Meissner A, West AE, Griffith EC et al. Derepression of BDNF transcription involves calcium-dependent phosphorylation of MeCP2. Science 2003; 302: 885-889.

81. Rivera $\mathrm{C}$, Li H, Thomas-Crusells J, Lahtinen H, Viitanen $\mathrm{T}$, Nanobashvili A et al. BDNFinduced TrkB activation down-regulates the $\mathrm{K}+-\mathrm{Cl}$ - cotransporter $\mathrm{KCC} 2$ and impairs neuronal $\mathrm{Cl}$ - extrusion. J Cell Biol 2002; 159: 747-752.

82. Ludwig A, Uvarov P, Soni S, Thomas-Crusells J, Airaksinen MS, Rivera C. Early growth response 4 mediates bdnf induction of potassium chloride cotransporter 2 transcription. Jeurosci 2011: 31: 644-649.

83. Roullet FI, Wollaston L, deCatanzaro D, Foster JA. Behavioral and molecular changes in the mouse in response to prenatal exposure to the anti-epileptic drug valproic acid. Neuroscience 2010; 170: 514-522. 
84. Martinowich K, Hattori D, Wu H, Fouse S, He F, Hu Y et al. DNA methylation-related chromatin remodeling in activity-dependent Bdnf gene regulation. Science 2003; 302 890-893.

85. Chahrour M, Jung SY, Shaw C, Zhou XB, Wong STC, Qin J et al. MeCP2, a key contributor to neurological disease, activates and represses transcription. Science 2008; 320 $1224-1229$

86. Deeb TZ, Lee HHC, Walker JA, Davies PA, Moss SJ. Hyperpolarizing GABA ergic transmission depends on KCC2 function and membrane potential. Channels 2011; 5: 475-481.

87. Sipila ST, Schuchmann S, Voipio J, Yamada J, Kaila K. The cation-chloride cotransporter NKCC1 promotes sharp waves in the neonatal rat hippocampus. J Physiol 2006; 573: 765-773.
88. Li YJ, Cleary R, Kellogg M, Soul JS, Berry GT, Jensen FE. Sensitive isotope dilution liquid chromatography/tandem mass spectrometry method for quantitative analysis of bumetanide in serum and brain tissue. J Chromatogr B 2011; 879: 998-1002.

Translational Psychiatry is an open-access journal published by Nature Publishing Group. This work is licensed under the Creative Commons Attribution-NonCommercialShare Alike 3.0 Unported License. To view a copy of this license, visit http://creativecommons.org/licenses/by-nc-sa/3.0/

Supplementary Information accompanies the paper on the Translational Psychiatry website (http://www.nature.com/tp) 